\title{
First and Second Derivative Spectrophotometric Methods for Determination of Paliperidone in Pharmaceutical Formulation
}

\author{
V. V. Nishanth. G \\ Department of Pharmaceutical Chemistry \\ JSS College of Pharmacy, JSS Academy of Higher \\ Education and Research, \\ Shivarathreeshwara Nagar, Bannimantap, \\ Mysuru - 570015, Karnataka, India
}

\author{
Dr. B. M. Gurupadayya \\ Professor \\ Coordinator-M.Pharm Pharmaceutical Analysis \\ Dept. of Pharmaceutical chemistry, \\ JSS College of Pharmacy, \\ JSS Academy of Higher Education and Research \\ Shivarathreeshwara Nagar, Bannimantap, \\ Mysuru- 570015, Karnataka, India.
}

\begin{abstract}
Simple, fast and reliable derivative spectrophotometric methods were developed for determination of paliperidone in bulk and pharmaceutical dosage forms. The solutions of standard and the sample were prepared in methanol. The quantitative determination of the drug was carried out using the first derivative values measured at $248 \mathrm{~nm}$ and the second derivative values measured at $246 \mathrm{~nm}(\mathrm{n}=6)$. Calibration graphs constructed at their wavelengths of determination were linear in the concentration range of paliperidone using $2-10 \mu \mathrm{g} / \mathrm{ml}$ for first and second derivative spectrophotometric method. The calibration graphs constructed at their wavelength of determination were found to be linear for $\mathrm{UV}$ and derivative spectrophotometric methods. All the proposed methods have been extensively validated as per ICH guidelines. There was no significant difference between the performance of the proposed methods regarding the mean values and standard deviations. Developed spectrophotometric methods in this study are simple, accurate, precise, specific, sensitive, and reproducible and can be directly and easily applied to pharmaceutical dosage form.
\end{abstract}

Keywords: Paliperidone, Derivative spectrophotometric, First derivative spectrum, Second derivative spectrum.

\section{INTRODUCTION:}

Paliperidone is the major active metabolite of risperidone which is a widely used as atypical antipsychotic ((Sherje and Londhe 2015)). Paliperidone is a benzisoxazole derivative and approved for the treatment of schizophrenia ((Mathew, Joshi Chintankumar, and Jonils 2011)) and other psychiatric disorders Chemically it is $( \pm)$-3-[2-[4-(6-fluoro1,2benzisoxazol-3-yl)-1-piperidinyl]ethyl]-6,7,8,9-

tetrahydro-9-hydroxy-2-methyl-4Hpyrido[1,2-a]pyrimidin4-one with empirical formula $\mathrm{C}_{23} \mathrm{H}_{27} \mathrm{FN}_{4} \mathrm{O}_{3}$ and molecular weight 426.49 ((Nageswara Rao, Ganapaty, and Lakshmana Rao 2013).

Specific mechanism is not know. Its therapeutic effect may be due to combination of $\mathrm{D}_{2}$ and 5-HT receptor antagonism (Barbosa et al. 2012)). Paliperidone has an antagonistic effect on $\alpha_{1}$ and $\alpha_{2}$ adrenergic receptors and H1 histaminic receptors ((Mathew, Joshi Chintankumar, and Jonils 2011)). The drug was approved on December 20, 2006 by the United States Food and Drug Administration (FDA)
(Trivedi et al. 2013)). Extensive literature survey reveals RP-HPLC method ((Nageswara Rao, Ganapaty, and Lakshmana Rao 2013; Jadhav et al. 2011)) Extraction Procedure and Chromatographic Analysis (Trivedi et al. 2013)). Stress degradation studies ((Chaudhari et al. 2013)). UFLC method ((Bindu, Dhekale, et al. 2012)) Spectrophotometric Method (Nagar and Pradesh 2014; Davidson et al. 2007))Derivative spectrophotometry is an analytical technique of great utility for extracting both qualitative and quantitative information from spectra composed of unresolved bands, and for eliminating the effect of baseline shifts and baseline tilts(Swarnalatha et al. 2014)

Other methods for determination of paliperidone:-

Reverse phase HPLC method: - This was developed and validated for the assay of paliperidone in pure and tablets. Analysis was carried out on Shimadzu HPLC model equipped with inertsil, LC-10AT pump, inertsil ODS C-18 column variable wavelength programmable UV-Detector SPD-10AVP and rheodyne injector with $20 \mu \mathrm{L}$ fixed loop. Acetonitrile and methanol in the ratio $10: 90 \mathrm{v} / \mathrm{v}$ at a flow rate of $1.0 \mathrm{~mL} / \mathrm{min}$ was employed for elution and the components were detected at $235 \mathrm{~nm}$ at ambient temperature. The method was validated as per the ICH guidelines. The retention time for paliperidone was found to be $5.67 \mathrm{~min}$. Linearity was observed in the concentration range of 20-120 ppm with correlation coefficient 0.9990 . The percent of relative standard deviation of six replicate measurements was found to be 1.25 indicate that the proposed method was precise. Recovery studies were conducted at three different concentration levels within the linearity limits and the average percent of recovery was 99.56. The amount of paliperidone drug content present in tablet dosage form was determined and found to be $99.80 \%$. Therefore, the developed method was simple, precise and accurate and can be successfully applied for the estimation of paliperidone in pharmaceutical dosage forms (( et al. 2012)

UPLC Method: - This method is applicable to the quantification of related substances and assay of Paliperidone palmitate. Chromatographic separation was 
achieved on Acquity UPLC BEH $(50 \mathrm{~mm}, 2.1 \mathrm{~mm}$, and $1.7 \mu \mathrm{m}) \mathrm{C}-18$ column, and the impurities are eluted with a gradient program of runtime about $10.0 \mathrm{~min}(\mathrm{Chen}$ et al. 2014)). The eluted compounds were monitored at $238 \mathrm{~nm}$, the flow rate was $0.5 \mathrm{~mL} / \mathrm{min}$, and the column oven temperature was maintained at $35^{\circ} \mathrm{C}$. The resolution of Paliperidone palmitate and eight (potential, bi-products and degradation) impurities was greater than 2.0 for all pairs of components. The high correlation coefficient ( $\mathrm{r} 2>0.999)$ values indicated clear correlations between the investigated compound concentrations and their peak areas within the test ranges. The repeatability and intermediate precision, expressed by RSD, were less than $10.0 \%$. The accuracy and validity of the method were further ascertained by performing recovery studies via a spike method. The accuracy of the method expressed as relative error was satisfactory. The drug was subjected to the International Conference on Harmonization (ICH) prescribed hydrolytic, oxidative, photolytic, and thermal stress conditions. The performance of the method was validated according to the present ICH guidelines for specificity, limit of detection, limit of quantification, linearity, accuracy, precision, ruggedness, and robustness. (Bindu, Dhekale, et al. 2012)

Four simple, sensitive, rapid and accurate analytical methods have been developed for the estimation of paliperidone in bulk and pharmaceutical dosage forms.

Method I was a precise reverse phase HPLC involving an isocratic elution of Paliperidone in a column of Pkenomenex CIS, using a mobile phase composition of acetonitrile: Methanol: Potassium dihydrogen phosphate $(45: 30: 25, \mathrm{v} / \mathrm{v})$. The flow rate was $1.0 \mathrm{ml} / \mathrm{min}$ and the effluent was monitored at $275 \mathrm{~nm}$ and retention time was observedat $4.15 \mathrm{~mm}$. Forced de-gradation studies were carried out in acid and basic medium,oxidative degradation in $\mathrm{H} 2 \mathrm{O} 2$ and as well as uv pho-to stability studies((Sherje and Londhe 2015; Bindu, Reddy, et al. 2012).

Method II \& III are visible spectrophotometnc methods based on the formation of red coloured complex between Paliperidone and PDACA which showed linearity in the concentration range $20-120 \mu \mathrm{g} / \mathrm{ml}$ and between Paliperidone and 4 Amino phenazone in red coloured chromogen which obeyed Beer's law 30-150 $\mu \mathrm{g} / \mathrm{ml}$ at absorbance maxima of $460 \mathrm{~nm}$ and $532 \mathrm{~nm}$ respectively ((Rele 2017a; 2017b)

Method IV was a simple ultraviolet spectroscopic method was developed for the estimation of Paliperidone in $0.1 \mathrm{~N}$ $\mathrm{HC} 1$ which obeyed Beer's law in the linearity range 5-25 $\mu \mathrm{g} / \mathrm{ml}$ at $275 \mathrm{~nm}$. The proposed methods are optimized and validated as per the ICH guidelines (Patil and Shirkhedkar 2015). Recovery of paliperidone in the proposed methods was found to be in the range of 97.5-99.2\%. The proposed methods can be used for routine analysis for the estimation of paliperidone in formulations. ((Mathew, Joshi Chintankumar, and Jonils 2011)

Derivative spectroscopy is a simple, sensitive, rapid, accurate, precise and economical methods for the estimation of paliperidone by UV, first and second derivative spectrophotometric methods in tablet formulation. Or

Derivative spectroscopy is a simple sensitive and economical method with minimal reagents and development period when compared with other analytical techniques

The current study focuses on developing a simple, sensitive novel derivative spectrophotometric methods for the estimation of Paliperidone in pure and pharmaceutical formulation and validate the method using standard ICH guidelines.((Davidson et al. 2007)

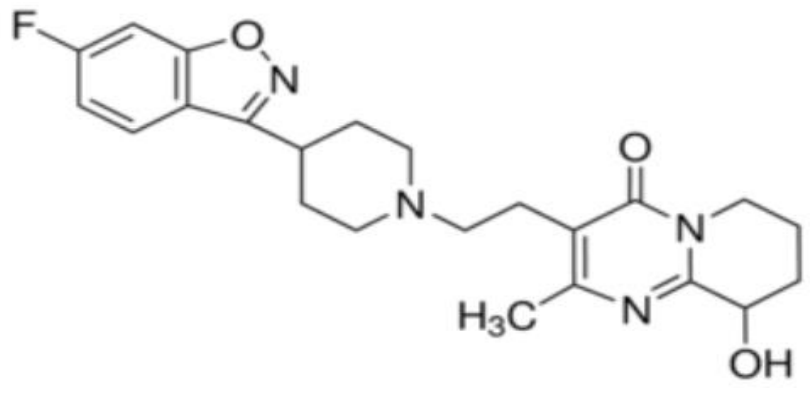

Figure 1: Chemical structure of paliperidone

\section{MATERIALS AND METHODS}

\section{INSTRUMENTATION:}

UV and derivative spectra of the solutions were recorded on double beam UV-Vis spectrophotometer Shimadzu1800 using $10 \mathrm{~mm}$ path length quartz cells with fixed slit width of $2 \mathrm{~nm}$ at a scanning speed of $1000 \mathrm{~nm} / \mathrm{min}$ scan range of $200-400 \mathrm{~nm}$, data pitch $0.5 \mathrm{~nm}$.

\section{CHEMICALS:}

Paliperidone pure sample was obtained as a gift sample from RL fine chemicals ltd, Bangalore, India. Tablet formulation (Palido OD 3, Torrent Pharmaceuticals Ltd, India) containing $3 \mathrm{mg}$ paliperidone was purchased from the local pharmacy. Methanol used was of analytical grade and was purchased from Merck Chemicals, India.

\section{SELECTION OF SOLVENT:}

Paliperidone is soluble in methanol and derivative spectra of the drug showed zero crossing points. Hence methanol was selected as the solvent for the method. 
PREPARATION OF STANDARD SOLUTIONS:

Stock solution of $1000 \mu \mathrm{g} / \mathrm{ml}$ of paliperidone was prepared in methanol, for first and second derivative spectrophotometric analysis. The standard solutions were prepared by dilution of the stock solution with methanol in a concentration range of 2, 4, 6, 8 and $10 \mu \mathrm{g} / \mathrm{ml}$ for first and second derivative spectrophotometric methods. Methanol was used as a blank solution.

\section{ASSAY PROCEDURE:}

A total of 20 tablets of paliperidone were accurately weighed and powdered. An amount of tablet triturate equivalent to label claim of paliperidone was weighed and transferred in $10 \mathrm{ml}$ calibrated volumetric flask, diluted with methanol stirred for about $45 \mathrm{~min}$ and then volume made up with methanol. This solution was filtered to remove any insoluble matter. The filtrate was collected in a clean volumetric flask. Appropriate dilutions were made to obtain $10 \mu \mathrm{g} / \mathrm{ml}$ with methanol from stock solution for both UV and derivative spectrophotometric methods( Table 7).

\section{VALIDATION:}

The proposed method was validated according to the International Conference on Harmonization (ICH) guidelines $^{8}$.

\section{LINEARITY:}

From the standard stock solution of paliperidone, appropriate aliquots were pipetted out in to

A series of volumetric flasks and volume was made up with methanol to get concentrations of $2-10 \mu \mathrm{g} / \mathrm{ml}$. Absorbances of these solutions was measured at 279 for zero order spectroscopy, 248 for first order derivative spectroscopy and at $246 \mathrm{~nm}$ for second order spectroscopy.
Standard graphs of linearity for proposed methods Results were shown in Table 1, Table 2 and Table 3.

\section{PRECISION:}

To evaluate the precision of the method, pure drug solution (Within the Linearity range of $2-10 \mu \mathrm{g} / \mathrm{ml}$ ) was analyzed and being repeated six times. The relative error $(\%)$ and relative standard deviation (\%) were less than 2.0 and indicate the high precision for the proposed methods (Table 4).

\section{L.O.Q and L.O.D}

The limits of detection and quantification of the proposed method was also analysed and reported (Table 5).

\section{ACCURACY:}

To assure the reliability of the above method recovery studies were carried out by mixing a known quantity of the standard drug with the formulation sample. The recovery studies were carried out at three different levels i.e. $80 \%$, $100 \%$ and $120 \%$ levels. The contents were analyzed by the proposed method for UV, first and second derivative spectroscopy (Table 6).

\section{RESULTS AND DISCUSSION}

\section{Linearity:}

The UV, first and second derivative spectra for paliperidone were recorded at the wavelength of $279 \mathrm{~nm}$, $248 \mathrm{~nm}, 246 \mathrm{~nm}$ respectively (Figure3, Figure 5 and Figure 7). The proposed method was found that the drug obeys linearity with in concentration range of $2-10 \mu \mathrm{g} / \mathrm{ml}$ (Table 1, Table 2 and Table 3) and (Figure 2, Figure 4 and Figure 6)

Table 1: Linearity of UV for Paliperidone

\begin{tabular}{|c|c|c|}
\hline Slno & Concentration & Absorbance \\
\hline 1 & 2 & 0.068 \\
\hline 2 & 4 & 0.084 \\
\hline 3 & 6 & 0.16 \\
\hline 4 & 8 & 0.196 \\
\hline 5 & 10 & 0.256 \\
\hline \multicolumn{2}{|c|}{ Slope $=0.0249$, Intercept 0.003, Correlation coefficient $=0.9841$} \\
\hline
\end{tabular}

Figure 2: Calibration curve of UV for Paliperidone

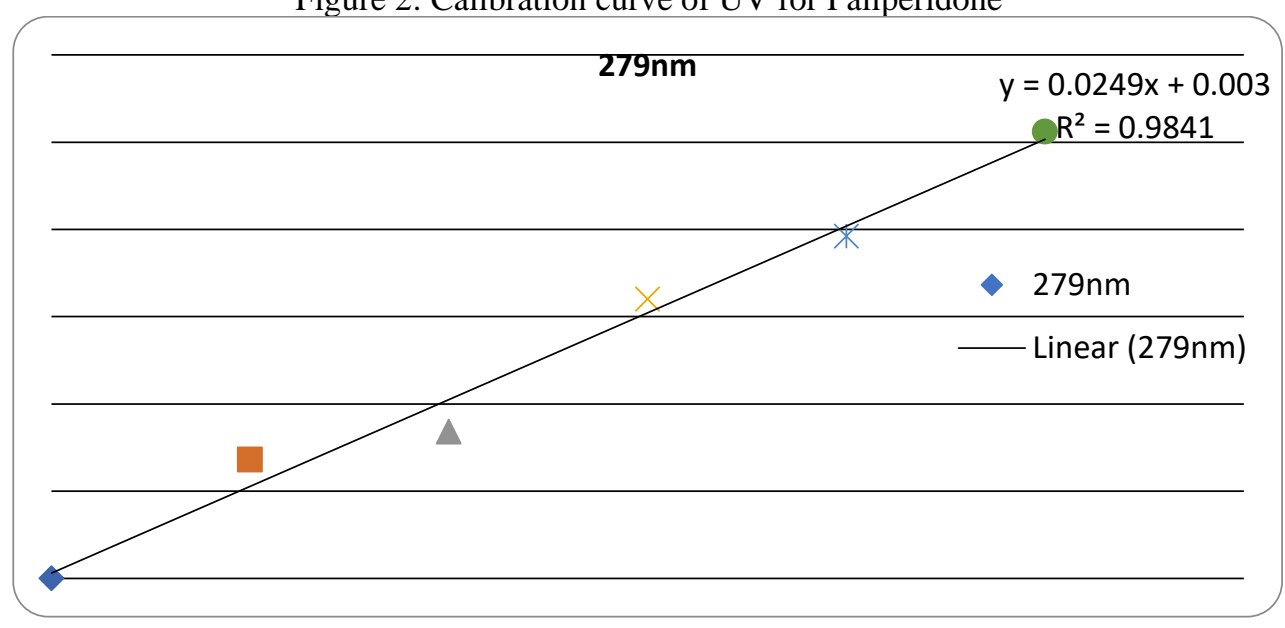


Figure 3: Overlay spectra of UV

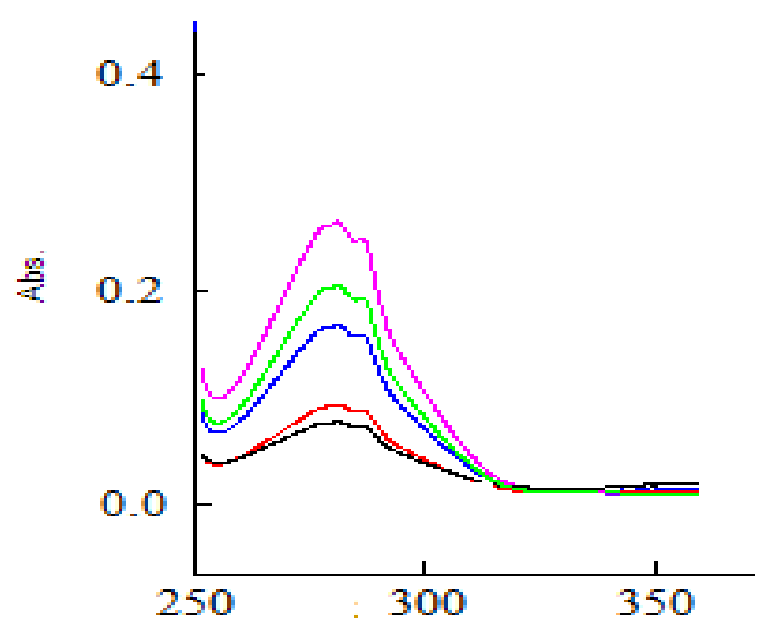

Table 2: Linearity first derivative

\begin{tabular}{|c|c|c|}
\hline Slno & Concentration & Absorbance \\
\hline 1 & 2 & -0.005 \\
\hline 2 & 4 & -0.008 \\
\hline 3 & 6 & -0.013 \\
\hline 4 & 8 & -0.016 \\
\hline 5 & 10 & -0.021 \\
\hline \multicolumn{2}{|c|}{ Slope $=-0.002$, Intercept $=-0.006$, Correlation coefficient $=0.9926$} \\
\hline
\end{tabular}

Figure 4: Calibration curve of first derivative

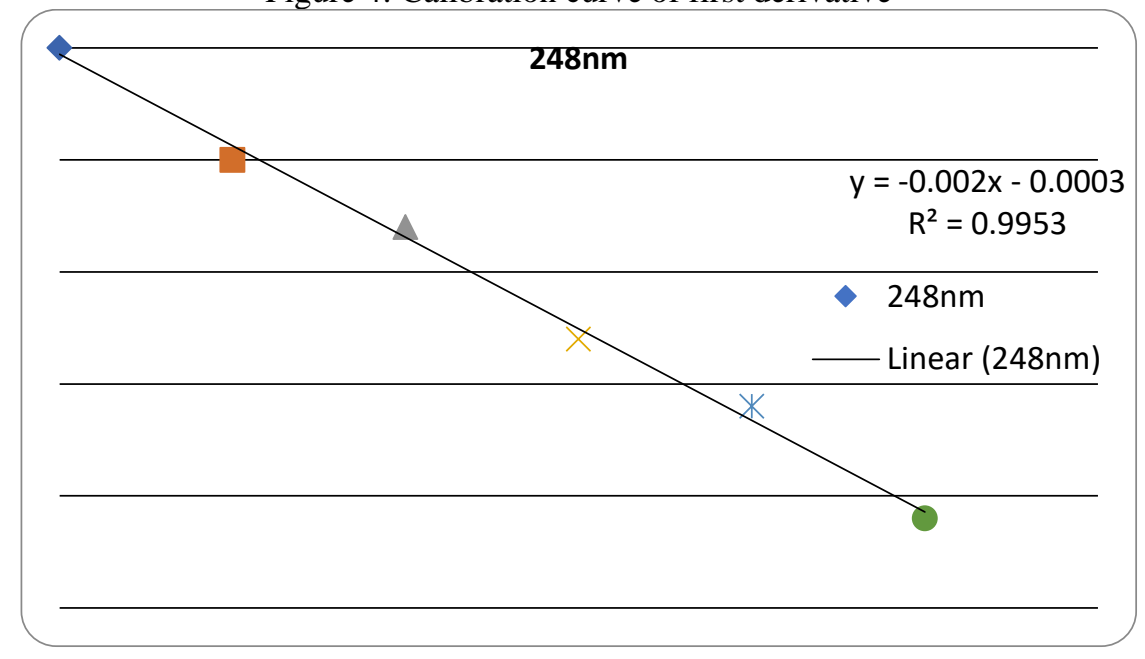


Figure 5: Overlay spectra of first derivative

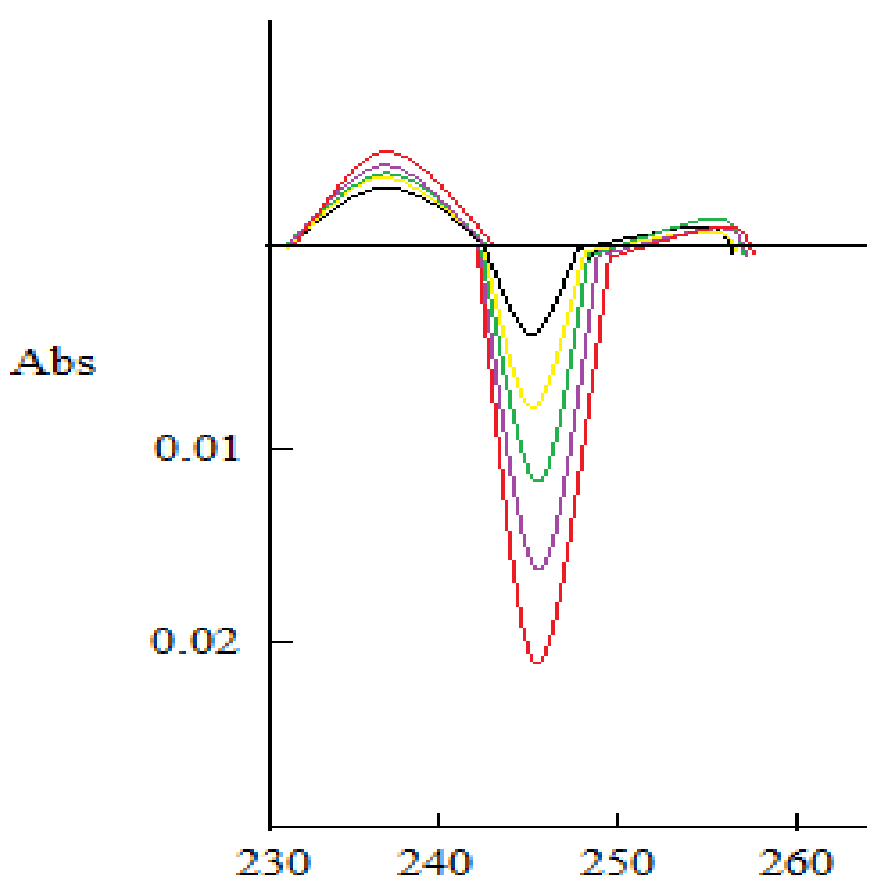

Table 3: Linearity of second derivative

\begin{tabular}{|c|c|c|}
\hline Slno & Concentration & Absorbance \\
\hline 1 & 2 & -0.002 \\
\hline 2 & 4 & -0.003 \\
\hline 3 & 6 & -0.004 \\
\hline 4 & 8 & -0.005 \\
\hline 5 & 10 & -0.006 \\
\hline \multicolumn{2}{|c|}{ Slope $=-0.0006$, Intercept=-0.0005, Correlation coefficient $=0.9796$} \\
\hline
\end{tabular}

Figure 6: Calibration curve of second derivative

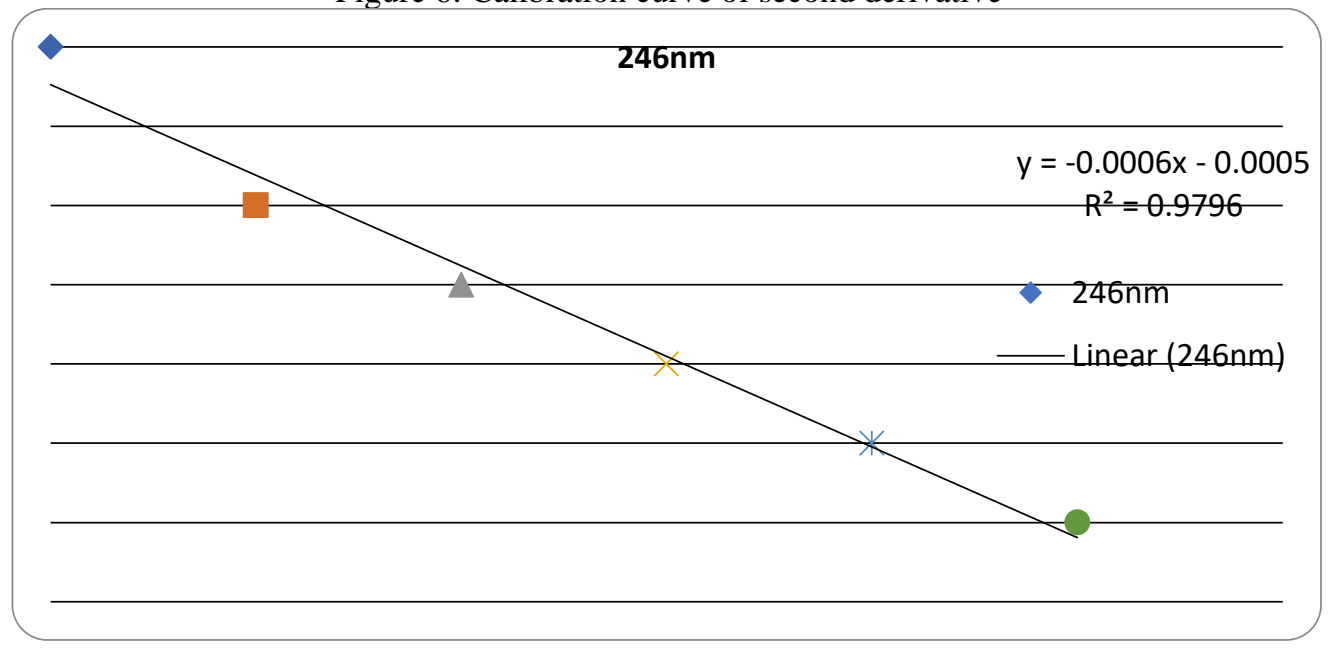


Figure 7: overlay spectra of second derivative

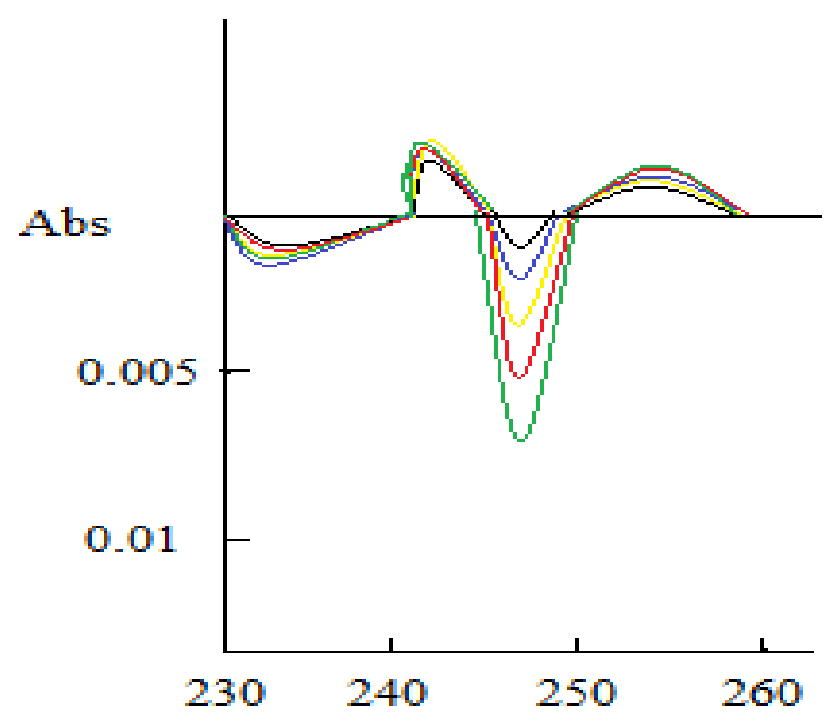

PRECISION:

From the precision studies it was found that the $\%$ RSD was less than $2 \%$ which indicates that the method has good reproducibility. To determine the precision of the method, paliperidone solution of concentration $6 \mu \mathrm{g} / \mathrm{ml} \mathrm{was}$ analyzed six times for UV, first and second derivative spectrophotometric methods (Table 4).

Table 4: Precision data for paliperidone.

\begin{tabular}{|c|c|c|c|c|c|c|c|}
\hline \multirow{3}{*}{ Slno } & \multirow{3}{*}{ Concentration } & \multicolumn{6}{|c|}{ Absorbance } \\
\hline & & \multicolumn{3}{|c|}{ Intraday precision } & \multicolumn{3}{|c|}{ Interday precision } \\
\hline & & UV & First derivative & $\begin{array}{c}\text { Second } \\
\text { derivative }\end{array}$ & UV & First derivative & $\begin{array}{c}\text { Second } \\
\text { derivative }\end{array}$ \\
\hline 1 & 6 & 0.164 & -0.0131 & -0.004 & 0.158 & -0.0129 & -0.0038 \\
\hline 2 & 6 & 0.161 & -0.013 & -0.0039 & 0.156 & -0.0128 & -0.0038 \\
\hline 3 & 6 & 0.16 & -0.0132 & -0.0041 & 0.159 & -0.0129 & -0.0039 \\
\hline 4 & 6 & 0.162 & -0.0131 & -0.004 & 0.157 & -0.0127 & -0.0038 \\
\hline 5 & 6 & 0.162 & -0.013 & -0.0041 & 0.157 & -0.0129 & -0.0039 \\
\hline 6 & 6 & 0.160 & -0.0132 & -0.0041 & 0.158 & -0.0128 & -0.0038 \\
\hline
\end{tabular}

\section{LOD and LOQ:}

The LOD and LOQ values of paliperidone for UV, first and second derivative were recorded (Table 5)

Table 5: LOD and LOQ of paliperidone

\begin{tabular}{|c|c|c|c|}
\hline & $\mathrm{UV}$ & First derivative & Second derivative \\
\hline LOD & $0.397 \mu \mathrm{g}$ & $0.272 \mu \mathrm{g}$ & $0.25 \mu \mathrm{g}$ \\
\hline LOQ & $1.204 \mu \mathrm{g}$ & $1.038 \mu \mathrm{g}$ & $0.897 \mu \mathrm{g}$ \\
\hline
\end{tabular}

Accuracy:

The \% recovery values of indicates that the method is accurate and reveals that commonly used excipients and additives present in the pharmaceutical formulations did not interfere in the proposed method. (Table 6)

Table 6: \% recovery of paliperidone

\begin{tabular}{|c|c|c|c|}
\hline & UV & First derivative & Second derivative \\
\hline $80 \%$ & $98.14 \%$ & $101 \%$ & $101.51 \%$ \\
\hline $100 \%$ & $98.75 \%$ & $99.01 \%$ & $99.87 \%$ \\
\hline $120 \%$ & $99.17 \%$ & $100.12 \%$ & $100.75 \%$ \\
\hline
\end{tabular}

\section{Assay of marketed formulation:}

Percentage of paliperidone in the marketed formulation was calculated and reported (Table 7). 
Table 7: Assay of marketed formulation

\begin{tabular}{|c|c|c|c|c|c|}
\hline & Brand name & Available form & Label claim & Amount found & Assay \\
\hline UV & Palido & Tablet & $3 \mathrm{mg}$ & 2.931 & $97.7 \%$ \\
\hline First derivative & Palido & Tablet & $3 \mathrm{mg}$ & 2.962 & 98.73 \\
\hline Second derivative & Palido & Tablet & $3 \mathrm{mg}$ & 2.989 & 99.63 \\
\hline
\end{tabular}

\section{CONCLUSION:}

Due to high sensitivity and simple sample preparation, the methods described can be used for undergraduate studies. Moreover simple spectrophotometric methods have obvious advantages over sophisticated instrumental analysis such as HPLC. This method was validated for precision, linearity and accuracy as per ICH guidelines. All the above parameters lead to the conclusion that the proposed method is accurate, precise, simple, sensitive and cost effective and can be applied successfully for the routine estimation of paliperidone in bulk and pharmaceutical formulation.

\section{REFERENCES:}

[1] Barbosa, Fábio, Luciano Mantovani, Cássia V. Garcia, and Andreas S. L. Mendez. 2012. "Studies on Paliperidone in OROS Tablets: Extraction Procedure and Chromatographic Analysis." ISRN Chromatography 2012: 1-9. https://doi.org/10.5402/2012/582375.

[2] Bindu, K. Hima, Nitin Haridas Dhekale, M. V. Suryanarayana, and Y. Anjaneyulu. 2012. "A Validated Stability Indicating UPLC Method for Simultaneous Determination of Assay, Related Substances, and Degradation Products of Paliperidone Palmitate Active Pharmaceutical Ingredient and Its Pharmaceutical Injection Forms." Journal of Liquid Chromatography and Related Technologies $\quad 35 \quad$ (4): $\quad$ 533-46. https://doi.org/10.1080/10826076.2011.601503.

[3] Bindu, K. Hima, I. Ugandar Reddy, Y. Anjaneyulu, and M. V. Suryanarayana. 2012. "A Stability-Indicating Ultra-Performance Liquid Chromatographic Method for Estimation of Related Substances and Degradants in Paliperidone Active Pharmaceutical Ingredient and Its Pharmaceutical Dosage Forms." Journal of Chromatographic Science 50 (4): 368-72. https://doi.org/10.1093/chromsci/bms011.

[4] Chaudhari, Rajeshri D., Vishruti H. Choksi, Tanvi Divan, Bhavna A. Patel, and Shraddha J. Parmar. 2013. "Development and Validation of First Order Derivative Spectrophotometric Method for Estimation of Lacosamide in Bulk and Tablet Dosage Form." Asian Journal of Pharmaceutical and Clinical Research 6 (SUPPL.3): 162-64.

[5] Chen, Hongming, Longshan Zhao, Guangjing Li, Donglei Leng, Panqin Ma, Lijin Tong, and Tianhong Zhang. 2014. "Development and Validation of a Rapid Andsensitive UHPLCMS/MS Method for Thedetermination of Paliperidone in Beagle Dog Plasma." Asian Journal of Pharmaceutical Sciences 9 (5): 286-92. https://doi.org/10.1016/j.ajps.2014.07.008.

[6] Davidson, Michael, Robin Emsley, Michelle Kramer, Lisa Ford, Guohua Pan, Pilar Lim, and Mariëlle Eerdekens. 2007. "Efficacy, Safety and Early Response of Paliperidone Extended-Release Tablets (Paliperidone ER): Results of a 6-Week, Randomized, Placebo-Controlled Study." Schizophrenia Research 93 (1-3): 117-30. https://doi.org/10.1016/j.schres.2007.03.003.

[7] Jadhav, Sanjay A., Shashikant B. Landge, Pramod M. Choudhari, Pavankumar V. Solanki, Saroj R. Bembalkar, and Vijayavitthal T. Mathad. 2011. "Stress Degradation Behavior of Paliperidone, an Antipsychotic Drug, and Development of Suitable StabilityIndicating RP-LC Method." Chromatography Research International 2011: 1-10. https://doi.org/10.4061/2011/256812.

[8] Mathew, Jane, K. Joshi Chintankumar, and Aghera Jonils. 2011. "Analytical Methods for the Estimation of Paliperidone." International Journal of Research in Pharmaceutical Sciences 2 (2): 158-61
[9] Nagar, Nagarjuna, and Andhra Pradesh. 2014 "Spectrophotometric Methods for the Quantitative Estimation of Paliperidone in Formulations." Chemical Science Transactions 3 (3): 1156-62. https://doi.org/10.7598/cst2014.771.

[10] Nageswara Rao, K., S. Ganapaty, and A. Lakshmana Rao. 2013. "Development and Validation of New HPLC Method for the Estimation of Paliperidone in Pharmaceutical Dosage Forms." Rasayan Journal of Chemistry 6 (1): 34-38.

[11] Patil, Sayali V, and Atul A Shirkhedkar. 2015. "APPLICATION OF UV-SPECTROPHOTOMETRY AND RP-HPTLC METHODS FOR ESTIMATION OF PALIPERIDONE IN BULK AND TABLETS" 6 (3): 2770-76.

[12] Rele, Rajan V. 2017a. "Spectrophotometric Estimation of Paliperidone in Bulk Drug and Pharmaceutical Dosage Form by Area under Curve Method." Research Journal of Pharmacy and Technology 10 (1): 31-34. https://doi.org/10.5958/0974360X.2017.00008.7.

[13] - 2017b. "UV-Spectrophotometric Estimation of Paliperidone by Derivative Method in Pharmaceutical Dosage Form." Research Journal of Pharmacy and Technology 10 (2) 396. https://doi.org/10.5958/0974-360x.2017.00080.4.

[14] Sherje, Atul P., and Vaishali Londhe. 2015. "Stability Indicating HPLC Method for Determination of Paliperidone in Bulk." International Journal of PharmTech Research 8 (8): 157-63.

[15] Swarnalatha, G, B Vijayakumar, D Jothieswari, P Jaya Chandra Reddy, and M Mohankumar. 2014. "Method Development and Validation of RP-HPLC Method for Determination of New Antipsychotic Agent in Paliperidone Palmitate Bulk Drug." International Journal of Novel Trends in Pharmaceutical Sciences 4 (4): 101-10.

[16] Trivedi, Rakshit Kanubhai, Prashant Jain, Mukesh C. Patel, Parimal M. Chatrabhuji, and Dipika R. Trivedi. 2013. "A Rapid, Stability Indicating RP-UPLC Method for Determination of Paliperidone Palmitate in a Depot Injectable Formulation." Journal of Applied Pharmaceutical Science 3 (7): 87-92. https://doi.org/10.7324/JAPS.2013.3716.

[17] K. UMAMAHESSWAR, G. RAMU, and C. RAMBABU. 2012 "A Reverse Phase HPLC Method Development and Validation for the Determination of Paliperidone in Pure and Dosage Forms." Chemical Science Transactions 2 (1): 41-46. https://doi.org/10.7598/cst2013.268. 